\title{
Does Flipped Classroom Model Affect EFL Learners' Anxiety in English Speaking Performance?
}

\author{
https://doi.org/10.3991/ijet.v16i01.16955 \\ Mohamad Yahya Abdullah ( $\bowtie$ ) \\ Buraimi University College, Oman, Sultanate of Oman \\ Universiti Kebangsaan Malaysia, Selangor, Malaysia \\ mabdullah@buc. edu. om \\ Supyan Hussin, Kemboja Ismail \\ Universiti Kebangsaan Malaysia, Selangor, Malaysia
}

\begin{abstract}
Learners of English as a foreign language (EFL) face various challenges which impede their efforts to achieve English proficiency, especially in speaking performance. In response, this study sets out to use the Flipped Classroom Model (FCM) as a teaching method to investigate the effectiveness of the FCM on EFL learners' anxiety in English speaking performance. A mixedmethods research design was utilized whereby 27 Omani undergraduate students majoring in English as a foreign language at Buraimi University College (BUC), Sultanate of Oman were selected purposively as the subjects of the study. The collected data involved the Anxiety in English Speaking Performance Questionnaire (AESPQ) that was distributed in three stages: pre, midway and post the implementation of FCM. Another set of data was elicited in the focus group interviews and students' reflective journals. Findings indicated that after twelve weeks of using FCM, a considerable improvement occurred on EFL learners' anxiety in English speaking performance across time. The results of the One-way ANOVA showed that there were significant differences among the EFL learners' levels of anxiety in speaking English, F $(2,52)=111.492$, $\mathrm{P}<0.001, \eta 2=0.811$ ), and MANOVA results revealed that there was a significant difference between the four dimensions of AESPQ over time (Wilks Lambda $=0.017, \mathrm{~F}=134.718, \eta 2=0.983$ ). FCM was found to be appropriate to all the students in this study since it satisfied their needs and suited their learning styles. Essentially, the findings reported in this research would contribute to advancing English language teaching, not only in instructional design but also in promoting EFL instructors to be more interested in using FCM.
\end{abstract}

Keywords-Flipped Classroom Model, Anxiety, English Speaking Performance, EFL Learning Environment

\section{Introduction}

In the field of Second Language Acquisition (SLA), the term anxiety is associated with learning a second and foreign language; therefore, it is called second/foreign 
language anxiety. Horwitz [1] stated that foreign language anxiety is known as the common emotional reaction impacted one-third of EFL learners. It has been reported to hinder different types of learning and has a negative association with the process of foreign language learning. In terms of learning English speaking, Hashemi [2] contended that feeling of stress, dread, nervousness, and apprehension is creating a mental block that impacts negatively on the EFL learners' English speaking performance. Shedding the lights on language anxiety is deemed crucial to enable learners developing their target language skills, mainly speaking skills. The ample literature about speaking anxiety revealed that students who are anxious about making errors are not able to speak English confidently. It has been found that EFL learners experience a higher level of speech anxiety compared with the other the four macro language skills $[2,3,4,5,6]$. Elia and Irianti [7] contended that anxiety as one of the psychological factors contributes significantly to creating the 'frame of mind' which determines learners' achievement, mainly speaking performance. Besides, they concluded that anxiety is the essential causes to hinder EFL learners' speaking performance.

\section{Literature Review}

To rectify the issue of anxiety in English speaking performance, it is crucial to identify the causes of this anxiety in previous literature. Extensive evidence from the body of literature indicated several reasons which cause anxiety in English speaking performance. Firstly, Kenen et al. [7] evidenced that fear of committing mistakes caused oral communication apprehension for the EFL learners when they perform speaking in front of their classmates. Secondly, it was reported that fear of negative evaluation contributes significantly to speaking anxiety among Turkish EFL learners [4]. Thirdly, creating conventional and stressful classroom environment, devoting the teacher-centeredness, large class sizes contributed significantly to limited speaking time, and teachers' authoritative attitudes and beliefs about the language learning and teaching processes [2]. Fourthly, the unwillingness to communicate led to a lack of confidence and lost the natural performance of expressing meanings and feelings [6].Last but not least, lacking the opportunities of exposure to practice English speaking in and out of the classroom contributed drastically in the existence of foreign language anxiety among the EFL learners [8].

More interestingly, the previous studies that conducted to point out the factors caused the anxiety in English speaking performance stated a set of recommendations to alleviate the anxiety. Tanveer [3] recommended to spread the feeling of confidence among students by providing them with corrective and constructive feedback and to avoid giving summative feedback during speech activities. Mustapha [5] suggested that students prefer group discussion to avoid oral communication apprehension. Khan and Al-Mahrooqi [9] assert the positive thinking and peers' assistance in the classroom to create low anxiety, encouraging, and interactive environment. This kind of classroom would hence promote students to be more confident and motivated.

Despite all the attempts to explore the problem of anxiety in English speaking performance, far too little attention has been paid to remedy the teaching methods in the 
EFL context. Until recently, there have been no empirical investigations with regards to reducing EFL students' level of anxiety. Hence, the current study is a move towards alleviating the anxiety in English speaking performance by creating interactive, encouraging, and engaging classroom environment, exposing students to plenty of learning in-class and out-of-class activities, taking into consideration addressing all the causes of anxiety in English speaking performance.

\section{Theoretical Framework}

In this study, the theoretical base is underpinned from different concepts and principles drawn from different language theories. It would be vital to establish an alignment between pedagogical and technological considerations with the support of the principles that emerged from the notions of collaborative and active learning approaches. These principles should be adopted to be the theoretical basis for an English-speaking classroom to promote more creativity and better opportunity in fostering the learning process of English speaking. Additionally, there is a potential for using FCM to increase the supportive nature of the learning environment and to support more interaction and engagement in group and individual activities and yield positive consequences for students and help them thrive. In this kind of alignment, students would learn the various skills deemed necessary and convenient for them to attain success.

Over the last two decades, the emergence of various kinds of social network sites like Instagram, WhatsApp, Twitter, YouTube, Facebook, and Blog have contributed significantly to improve pedagogical practices. According to Liu [10], the widespread use of these applications has led to remarkable contributions to educational settings, such as in the processes of language teaching and learning. These contributions have created more productive learning environments, offering plenty of possibilities to render more flexible learning programs. The integration of technology in language learning and teaching has been implemented by different types of pedagogical models $[11,12]$. These models employ technology to increase the teacher's efficiency and students' productivity through enhancing the concept of student-centred education and the 21st-century learning environment [11]. Thus, the concept of the conventional classroom has started fading gradually and is being substituted by other notions built on a combination of both conventional and online learning, widely adopted in various pedagogical practices like the blended learning[13].

The progressive change from the conventional lecturing to the model of blended learning has paved the way for more flexible teaching approaches. The model of the flipped classroom incarnated the notion of the blended learning in which students are encouraged to contribute productively to their learning, develop their knowledge, and improve their communication skills collaboratively and actively with their teacher and peers $[14,15,16]$. Using FCM "allows students to study the basic concepts through electronic means and comprehend them in-depth in the classroom. This model enables students to spend class time to deliberate further with their instructor and peers" [15]. Its learning environment aims to combine the attributes of both online and conven- 
tional classroom instruction such as freedom to access information, efficiency, and authentic interaction with peers and the teacher within the classroom. The nature of FCM creates a link between conventional lecturing and online activities, grants the students authentic opportunities to be engaged in meaning negotiation and information sharing processes. More interestingly, the teacher plays the role of facilitator and guide of the learning process [17]. Using FCM embodies vital potentials to practise speaking without the time limitations and classroom pressure [15].

Consequently, students' language learning process would be more sustainable, productive, and independent [18]. It allows the teacher to design various speaking activities in an encouraging, engaging, interactive, and safe classroom environment. Positively investing time in class allows for more discussion, sharing of knowledge and ideas, and expression of feelings and thoughts. Students' anxiety in learning can be alleviated as they collaborate, interact, share feedback, and observe one another's speaking performance.

Accordingly, this study is hoped to make a noticeable contribution to the field of emerging technology in the language learning process. The main reason for undertaking this study is my belief that FCM is likely to have a positive impact on EFL students' level of anxiety in speaking performance- the evidence needs to be produced in setting out to implement the FCM as a teaching method, the results of which would indicate the extent of its effectiveness.

\section{$4 \quad$ Methodology}

In this study, a mixed-method research design was utilized, involving 27 Omani undergraduate students majoring in English as a foreign language at Buraimi University College (BUC), Sultanate of Oman were selected purposively as the subjects of the study. The sampling includes all students who registered in the course of Advanced Communication Skills. Purposive sampling refers to selecting a sample based entirely on own researcher knowledge of the population and the nature of the research objective [19].

\subsection{Data collection methods}

The current study fulfilled the exploration of the phenomenon within its context using a variety of data sources comprising both quantitative and qualitative methods to accomplish the objective of this research. Concerning the quantitative method, all participants of the present study $(n=27)$ responded to the Anxiety in English Speaking Performance Questionnaire which was administered in three stages: pre, midway, and post the implementation of FCM that lasted twelve weeks. Regarding the qualitative methods, the researcher extended an invitation to the participants $(n=27)$ of the study to write their reflective journals which consisted of three phases distributed through the twelve weeks of the FCM implementation. Besides, three groups of four students were selected to be involved in the focus group interviews at the end of the FCM 
implementation. They were selected based on their levels of speaking performance, including high, middle, and low levels.

Anxiety in English Speaking Performance Questionnaire (AESPQ): In this study, the researcher developed a questionnaire that measures Anxiety in English Speaking Performance Questionnaire (henceforth AESPQ) which fits its context. The items of this developed questionnaire were adapted from previous scales [20, 21, 22]. AESPQ is an 18-item self-report measurement that reflects learners' anxiety experience involved with English speaking performance (see the Appendix). The questionnaire items comprised four dimensions, including Verbal Communication (VC), Nonverbal Communication ( $\mathrm{NvC}$ ), Fear of Evaluation (FoE), and Speaking Activities (SAs) as shown in Table 1. The statistical results showed that the Cronbach's Alpha value for the AESPQ was 0.871 .

Table 1. Four Dimensions of the AESPQ

\begin{tabular}{|l|c|c|}
\hline \multicolumn{1}{|c|}{ Dimensions } & Total items (18) & Items no. \\
\hline VC & 7 & $1,2,3,4,5,6,7$ \\
\hline NvC & 3 & $8,9,10$ \\
\hline FoE & 4 & $11,12,13,14$ \\
\hline SAs & 4 & $15,16,17,18$ \\
\hline
\end{tabular}

AESPQ assesses the anxiety associated with VC through 7 items by answer questions like "I get nervous and forget words and ideas I know in English speaking class" and "I am confused and jumble my thoughts when I speak before the audience"; NvC through 3 items such as "I find it difficult to control my body movements while I am speaking in English"; FoE including four items which reflects the fear from teacher's and peers' feedback like "I get nervous if my classmates correct my errors while I am speaking in English"; SAs also comprising 4 items that report about the apprehension from engaging in any speaking activity (group, pair, or individual activities) such as "I get nervous in any speech activity because my English is poor". ASEPQ is designed on a 5-point Likert type ranging from 'strongly disagree to strongly agree' ( strongly disagree $=1$; disagree $=2$; neutral $=3$; agree $=4$; strongly agree $=5$ ).

\section{Data Analysis Methods}

The computer software of statistical packages for the social sciences (SPSS, version 21) was used to analyse the quantitative data. The one-way repeated measured (ANOVA) was performed to explore the effects of using FCM on EFL learners' anxiety in speaking English at three periods, including pre-, midway, and post the use of FCM. Moreover, one-way repeated measures multivariate analysis of variance (MANOVA) was run to show any differences occurred among the mean scores of the dimensions within the factor of anxiety over time. Besides, MANOVA, as stated in [23] "indicates whether the dimensions in each variable were significantly correlated". The quantitative data for univariate and multivariate normality was assessed with 
statistical tests and graphically to "ensure that all variables satisfied the assumption of normality distribution" [23].

Consequently, the statistical tests of skewness and kurtosis and the graphical test of Boxplot were performed. The results indicated that the values for all variables met the criteria of the normal distribution. The boxplot graphs showed that there were not any significant outliers while the skewness and kurtosis of the distribution showed that all values were between -2.0 and +2.0 . On the other hand, the qualitative data collected from the reflective journals and focus group interviews were analysed manually using thematic analysis.

\section{$6 \quad$ Results}

A one-way ANOVA was carried out to compare the mean scores of the EFL learners' anxiety in English speaking performance during the use of FCM through determining whether there were differences among these mean scores over time with a statistical test at Time 1 (before using FCM), Time 2, (after six weeks from the use of FCM), and Time 3 (after 12 weeks, i.e., after using the FCM). The means and standard deviations are presented in Table 2.

Table 2. Descriptive one-way ANOVA for anxiety

\begin{tabular}{|l|c|c|c|}
\hline \multicolumn{1}{|c|}{ Anxiety Tests } & Mean & Std. Deviation & N. of students \\
\hline Time 1 & 4.350 & 0.320 & 27 \\
\hline Time 2 & 3.147 & 0.730 & 27 \\
\hline Time 3 & 2.104 & 0.518 & 27 \\
\hline
\end{tabular}

Table 2 shows that the total mean of participants' anxiety $(\mathrm{N}=27)$ in Time 1 was (mean $=4.350 ; \mathrm{SD}=0.320$ ). The results of Time 2 recorded a noticeable decrease in the total mean score of the anxiety $($ mean $=3.147 ; \mathrm{SD}=0.730)$. Moreover, the total mean of anxiety showed a considerable decrease $($ mean $=2.104 ; \mathrm{SD}=0.5186)$ in Time 3. The results demonstrate a significant lessening occurred at the EFL learners' anxiety in English speaking performance across time.

Figure 1 shows that the percentage of the improvement that reported in participants' level of anxiety over time. The results of Time1 recorded a noticeable percentage of improvement of $27.66 \%$ of the participants' anxiety level compared with the Pre-test. Besides, the results of Time 2 revealed a much more significant improvement of $33.11 \%$ after 12 weeks form using FCM compared with the results of the baseline. What can be seen in Figure 1 is the progressive improvement of participants' anxiety in English speaking performance during the use of FCM. 


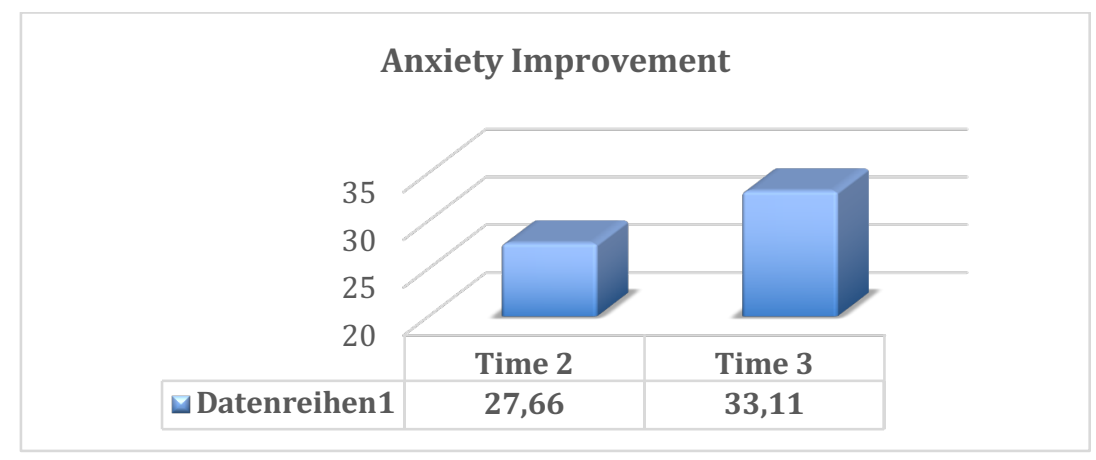

Fig. 1. Percentage of improvement for the anxiety compared with the Time 1

The inferential statistics were used to determine whether these recorded improvements were significant or not. The results of one-way ANOVA for the factor of anxiety over time revealed that differences among the anxiety tests were statistically significant $\left.\mathrm{F}\left(2,{ }_{52}\right)=111.492, \mathrm{P}<0.001, \eta 2=0.811\right)$. Furthermore, the Bonferroni post hoc test was performed to compare the mean scores and to evaluate the changes for mean differences of anxiety across the time. The results of the Bonferroni test, as shown in Table 3, illustrated the differences among all tests which were statistically significant $(\mathrm{p}<0.001)$.

Table 3. Pairwise comparison of anxiety over three times

\begin{tabular}{|c|c|c|c|c|c|c|c|}
\hline \multirow{2}{*}{ Measure } & (I) time & \multirow{2}{*}{$(\mathbf{J})$ time } & \multirow{2}{*}{$\begin{array}{c}\text { Mean Difference } \\
\text { (I-J) }\end{array}$} & \multirow{2}{*}{ SE } & \multirow{2}{*}{ P value } & \multicolumn{2}{|c|}{ 95\% CI } \\
\hline \multirow{3}{*}{ Time } & 1 & 2 & 1.204 & .157 & $<0.001$ & .802 & 1.605 \\
\cline { 2 - 8 } & 1 & 3 & $2.246^{*}$ & .121 & $<0.001$ & 1.936 & 2.556 \\
\cline { 2 - 8 } & 2 & 3 & $1.042^{*}$ & .170 & $<0.001$ & .608 & 1.476 \\
\hline
\end{tabular}

The one-way MANOVA was conducted to calculate the differences in the mean scores of participants' anxiety in English speaking performance including the dimensions of $\mathrm{VC}, \mathrm{NvC}, \mathrm{FoE}$, and $\mathrm{SAs}$, and to measure whether there were any differences among these four dimensions across the time. The results of MANOVA (Wilks Lambda $=0.017, \mathrm{~F}=134.718, \eta 2=0.983$ ) indicated that there was a significant difference between these four dimensions over time. The means and standard deviations are presented in Table 4. 
Table 4. Descriptive one-way MANOVA for anxiety

\begin{tabular}{|l|c|c|c|}
\hline \multicolumn{1}{|c|}{ Anxiety Tests } & Mean & Std. D. & N. of Sts \\
\hline Time 1-VC & 4.449 & 0.295 & 27 \\
\hline Time 2-VC & 3.190 & 0.680 & 27 \\
\hline Time 3-VC & 2.021 & 0.537 & 27 \\
\hline Time 1-NvC & 4.407 & 0.509 & 27 \\
\hline Time 2-NvC & 3.259 & 1.043 & 27 \\
\hline Time 3-NvC & 2.296 & 0.747 & 27 \\
\hline Time 1-FoE & 4.333 & 0.480 & 27 \\
\hline Time 2-FoE & 3.138 & 0.704 & 27 \\
\hline Time 3-FoE & 2.222 & 0.728 & 27 \\
\hline Time 1-SAs & 4.213 & 0.472 & 27 \\
\hline Time 2-SAs & 3.000 & 0.832 & 27 \\
\hline Time 3-SAs & 1.879 & 0.423 & \\
\hline
\end{tabular}

Table 4 shows that the dimension of VC reported three different mean scores over time, Time $1($ mean $=4.449 ; \mathrm{SD}=0.295)$, Time $2($ mean $=3.190 ; \mathrm{SD}=0.680)$, and Time 3 (mean $=2.021 ; \mathrm{SD}=0.680)$. Similarly, the dimension of $\mathrm{NvC}$ recorded three different mean scores over time, Time 1 (mean $=3.259$; $\mathrm{SD}=0.509)$, Time 2 (mean $=3.259 ; \mathrm{SD}=1.043)$, and Time $3($ mean $=2.296 ; \mathrm{SD}=0.747)$. Likewise, the dimension of FoE counted three different mean scores over time, Time 1 (mean $=4.333$; SD $=0.480)$, Time $2($ mean $=3.138 ; \mathrm{SD}=0.704)$, and Time $3($ mean $=2.222 ; \mathrm{SD}=0$. 728). Also, the dimension of SAs scored three different mean scores across the time, Time $1($ mean $=4.213 ; \mathrm{SD}=0.472)$, Time $2($ mean $=3.000 ; \mathrm{SD}=0.832)$, and Time $3($ mean $=1.879 ; \mathrm{SD}=0.423)$.

The results indicate that the four dimensions of anxiety in English speaking performance significantly were reduced across the time of FCM implementation. Figure 2 shows the changes that occurred in the four dimensions of the participants' anxiety levels during the use of FCM. What stands out in Figure 2 is the percentage improvement of the four dimensions of students' anxiety during the implementation of FCM.

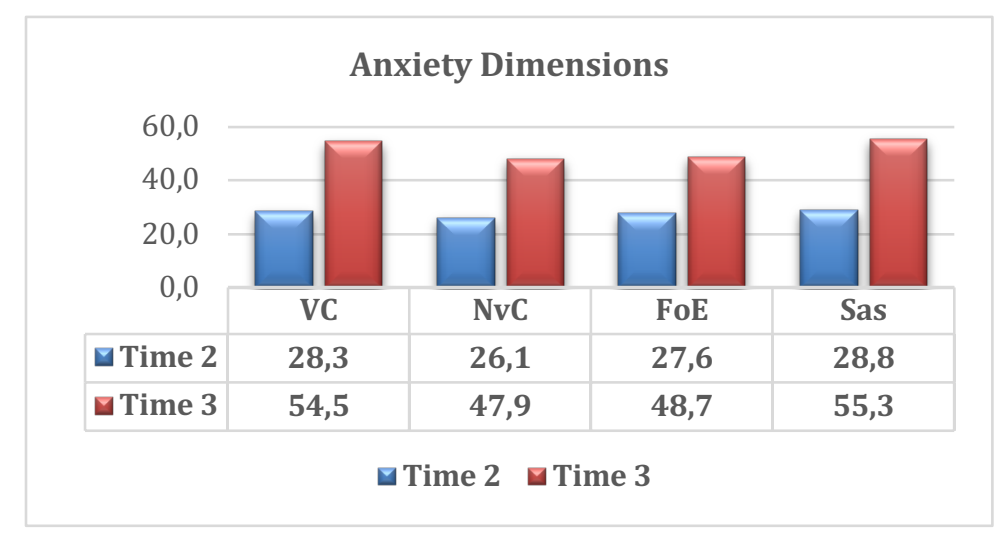

Fig. 2. Percentage of improvement for the four dimensions of anxiety compared to the Time 1 
Figure 2 illustrates the percentage improvement of the four dimensions of anxiety across the time of using FCM. The results of Time 2 and Time 3 revealed remarkable improvements for the four dimensions compared with the results of Time 1. Concerning the results of Time 2, the lowest improvement was in the dimension of NvC 26.05 $\%$ while the most significant improvement was recorded in the dimension of SAs $28.79 \%$. Besides, the dimension of $\mathrm{VC}$ reported $28.3 \%$, which is very close to the most significant recorded improvement. However, the dimension of the FoE reported $27.56 \%$.

Moreover, the results of Time 3 demonstrated a considerable improvement on all anxiety dimensions, whereas the order of the recorded percentage improvements from the highest to lowest was the same as what occurred in Time 2. The improvement for the dimensions was reported as $55.39 \%$ for the SAs, $54.58 \%$ for the VC, $48.72 \%$ for FoE, and $47.9 \%$ for the NvC. These findings indicate that the participants of the current research showed a noticeable tendency to decrease their anxiety levels in all the dimensions of the anxiety in English speaking performance over time of the FCM implementation. Then the inferential statistics were conducted to determine whether these observed improvements are significant.

The results of the one-way ANOVA for all dimensions revealed that the difference among the three times were statistically significant whereas the $\mathrm{VC}$ recorded $\mathrm{F}(2,52)$ $=142.659, \mathrm{P}<0.05, \eta 2=0.846)$, the $\mathrm{NvC}$ dimension counted $\mathrm{F}(2,52)=50.937$, $\mathrm{P}<0.05, \eta 2=0.662)$, the dimension of FoE resulted $\mathrm{F}(2,52)=71.834, \mathrm{P}<0.05, \eta 2=$ $0.734)$, and the dimension of SAs scored $F(1.457,37.890)=100.395, P<0.05, \eta 2=$ 0.794). Besides, the results of the ANOVA test showed that these dimensions were also statistically different across the three anxiety tests. Henceforth, the Bonferroni post hoc test was run to evaluate the effects of using FCM on each dimension and to compare their mean scores. Table 5 shows the results of the Bonferroni test, which indicated that the difference among most of the tests was statistically significant $(\mathrm{p}<0.001)$.

Table 5. Pairwise comparison of anxiety dimensions over time

\begin{tabular}{|c|c|c|c|c|c|c|c|}
\hline \multirow{2}{*}{ Measure } & \multirow{2}{*}{ (I) time } & \multirow{2}{*}{ (J) time } & \multirow{2}{*}{$\begin{array}{l}\text { Mean Difference } \\
\text { (I-J) }\end{array}$} & \multirow{2}{*}{ SE } & \multirow{2}{*}{$P$ value } & \multicolumn{2}{|c|}{$95 \%$ CI } \\
\hline & & & & & & $L B$ & $U B$ \\
\hline \multirow{3}{*}{$\mathrm{VC}$} & 1 & 2 & $1.259^{*}$ & .148 & $<0.001$ & .881 & 1.637 \\
\hline & 1 & 3 & $2.429^{*}$ & .116 & $<0.001$ & 2.131 & 2.726 \\
\hline & 2 & 3 & $1.169^{*}$ & .164 & $<0.001$ & .751 & 1.588 \\
\hline \multirow{3}{*}{$\mathrm{NvC}$} & 1 & 2 & $1.148^{*}$ & .222 & $<0.001$ & .579 & 1.717 \\
\hline & 1 & 3 & $2.111 *$ & .189 & $<0.001$ & 1.627 & 2.595 \\
\hline & 2 & 3 & $.963 *$ & .215 & $<0.001$ & .412 & 1.514 \\
\hline \multirow{3}{*}{ FoE } & 1 & 2 & 1.194* & .183 & $<0.001$ & .727 & 1.662 \\
\hline & 1 & 3 & $2.111^{*}$ & .169 & $<0.001$ & 1.679 & 2.543 \\
\hline & 2 & 3 & $.917^{*}$ & .178 & $<0.001$ & .461 & 1.372 \\
\hline \multirow{3}{*}{ SAs } & 1 & 2 & $1.213^{*}$ & .172 & $<0.001$ & .773 & 1.653 \\
\hline & 1 & 3 & $2.333^{*}$ & .108 & $<0.001$ & 2.056 & 2.611 \\
\hline & 2 & 3 & $1.120^{*}$ & .200 & $<0.001$ & .608 & 1.633 \\
\hline
\end{tabular}


According to this test, the results of pairwise comparison revealed that the mean difference for all dimensions was statistically significant $(\mathrm{P}<0.001)$ in the comparison between time 1 and time 2, time 1 and time 3 , and time 2 and time 3 . These results indicated that all dimensions of participants' anxiety in English speaking performance decreased significantly throughout the implementation of FCM. Also, this decrease might record higher scores with time.

Furthermore, the qualitative results coincide the quantitative ones where almost all participants reported positively the increasable improvement that happened to their anxiety in speaking English. According to the students' reflections, the majority agreed that their anxiety level started fading slowly after few weeks from using FCM. They indicated that their anxiety in English speaking performance had lessened remarkably over time. For example, S16 said that "After few weeks. I can say my anxiety level in my English-speaking performance became less because I speak a lot and participate more and more in the classroom, so it becomes a routine" (RJP2S16). Besides, after 12 weeks, the same student also stated that her anxiety has decreased to the extent that she can be involved in any speaking occasions "Anxiety level is almost faded. I become more confident when I perform anything in front of my classmates and the teacher" (RJP3S16). As one of the respondents who involved in the first focus group interview, S16 has asserted her reflections through her answer to the question of rating the anxiety level at the end of the semester, "at the beginning, I had some anxiety when I speak or when I am in front of my classmates, but at the end, the rate of anxiety is being low" (1stFGS16).

Similarly, S05 pointed out the decrease that occurred to her anxiety level gradually during the implementation of FCM. Her reflections in the second and third reflective journals, as well as her responses in the interview, were positive towards the effects of the application of FCM on her anxiety level in English speaking performance. The extracts mentioned below show her responses:

RJ2S05: The level of anxiety I felt has lessened that I am not ashamed and not worried about speaking in front of my classmates.

RJ3S05: The fear and anxiety decreased significantly because the FMC environment allowed me to practice speaking English continuously during the semester. In addition, I still feel more improvement in terms of anxiety and fear to speak on different occasions. (Translated)

1st FGS05: "In my opinion, I think flipped learning really helped me ... I really don't feel like nervous or afraid..."

Those above quantitative and qualitative results showed the positive effects of using FCM on students' anxiety level associated with English speaking performance. Summing up the overall mentioned findings, it can be concluded that the FCM was a vital and dynamic teaching technique that contributed effectively to decreasing EFL learners' anxiety in the English-speaking performance. 


\section{$7 \quad$ Discussion and Conclusion}

In this study, the quantitative and qualitative findings revealed that the use of FCM over twelve weeks was useful and exciting. The quantitative findings showed that the FCM was found to be a useful way of decreasing students' level of anxiety in English speaking performance. In addition, the results of the analysis of students' reflective journals and interview transcripts showed a remarkable degree of agreement with the quantitative results in terms of FCM positive effects on students' anxiety. Most interestingly, the majority of the students indicated that their willingness to speak English had increased over time. They also expressed the desire to continue practising different collaborative speaking activities inside and outside the classroom to increase their opportunities to practise speaking in English due to their satisfaction with the FCM learning environment. Hence, it can be concluded that the FCM was a vital and dynamic teaching technique that contributed effectively to alleviating EFL learners' anxiety in the English-speaking performance.

Further analysis of students' reflections and interview transcripts revealed the findings mentioned above could be attributed to the main characteristics of FCM implementation, such as delivered instructional video lectures that helped them be more confident and motivated since they were able to prepare themselves before coming to the classroom. This view highlights the positive role of the pre-preparation aspect in the learning process that helps students prepare for lectures and provides a basis for interactive learning $[15,24]$. The students could attend the lecture with well-prepared, having the confidence to answer questions and participate in classroom activities appropriately. This finding concurs with those of previous studies by Bergmann and Sams [24], Bishop et al. [25], and Çakiroğlu and Öztürk [26] which indicated the significant role of instructional video lectures in enhancing students' motivation and satisfaction with their learning process, and in granting more time for instructors to circulate the classroom, and enhancing the learning process by offering adequate feedback. The current study provides a new finding that the instructional video lectures utilized in FCM proved to be a considerable teaching method for improving students' anxiety in English speaking performance.

Moreover, the implementation of FCM freed up time that would otherwise be spent on the lecture, allowing students more conversational activities to practice speaking in English. The participants of the study believed that FCM had helped them become more enthusiastic and confident to speak English due to more opportunities to speak about different topics and be involved in various in-class and out-of-class conversational activities. Bishop et al. [25] suggested investing the in-class time in carrying out a wide variety of learning activities to allow more social interaction, construction of knowledge and sharing thoughts, according to the principles of collaborative and active learning approaches. Investing the class time in more opportunities will engage students in the process of meaningful negotiation and active interaction and enable students to be more active learners. The analysis of students' reflective journals and interview responses showed their positive views for their teacher's role, which was claimed to have contributed significantly in improving their motivation, selfconfidence and in reducing their anxiety in speaking English. Lightbown and Spada 
[27] suggested that "EFL teachers design their teaching based on their learners' needs and characteristics as this could contribute to motivating EFL learners to overcome language learning obstacles and weaknesses that hinder them from learning the target language". This finding is in a partial agreement with the findings of studies carried out by Kang [28] and Webb et al. [29] who believed that using FCM grants the teacher a highly significant and helpful role that enhances students' in-class interaction and maintains their learning goals.

Most interestingly, it was discovered that the students found the classroom environment attractive. They found their class a source of motivation, inspiration, and competition because of the peaceful, comfortable, and encouraging learning environment. This can be attributed to the alignment between the characteristics of FCM as a teaching method and the principles of collaborative and active learning approaches that underpinned this study. The characteristics of the FCM strengthened the collaborative and social interaction, helping students support each other's weaknesses as they worked together, sharing scaffolding information and knowledge, and also helped shy students to open up more and be more willing to accept other opinions [30].

Thus, in response to the objective of this study, it can be concluded that the qualitative and quantitative findings together indicated the positive effects of using FCM on EFL learners' level of anxiety in English speaking performance. The findings of the study have proven the effectiveness of the FCM implementation in creating the learning environment, which was reported as a key contributor to the progressive improvement of participants' anxiety. FCM was found to be appropriate to all the students in this study since it satisfied their needs and suited their learning styles. It is hoped that the findings reported in this study will be used to support and enhance the teaching and learning of English speaking in EFL classrooms.

\section{References}

[1] E. Horwitz, "Language anxiety and achievement," Annu. Rev. Appl. Linguist., vol. 21, pp. $112-126,2001$.

[2] M. Hashemi, "Language stress and anxiety among the English language learners," Procedia-Social Behav. Sci., vol. 30, pp. 1811-1816, 2011. https://doi.org/10.1016/j.sbspro.201 $\underline{1.10 .349}$

[3] M. Tanveer, "Investigation of the factors that cause language anxiety for ESL/EFL learners in learning speaking skills and the influence it casts on communication in the target language," Univ. Glas. Scotl., 2007.

[4] S. Aydin, "An Investigation on the Language Anxiety and Fear of Negative Evaluation among Turkish EFL Learners.," Online Submiss., 2008.

[5] W. Z. W. Mustapha, "ESL students communication apprehension and their choice of communicative activities," Asean J. Teach. Learn. High. Educ., vol. 2, no. 1, pp. 22-29, 2010.

[6] K. Yaikhong and S. Usaha, "A Measure of EFL Public Speaking Class Anxiety: Scale Development and Preliminary Validation and Reliability.," English Lang. Teach., vol. 5, no. 12, pp. 23-35, 2012. https://doi.org/10.5539/elt.v5n12p23

[7] F. Elia and D. Irianti, "Psychological factors that hinder students from speaking in English,” J. English Acad., vol. 2, no. 2, pp. 50-61, 2015. 
[8] R. Kenen, A. Arden-Jones, and R. Eeles, "We are talking, but are they listening? Communication patterns in families with a history of breast/ovarian cancer (HBOC)," PsychoOncology J. Psychol. Soc. Behav. Dimens. Cancer, vol. 13, no. 5, pp. 335-345, 2004. https ://doi.org/10.1002/pon.745

[9] A. Khan and R. Al-Mahrooqi, "EFL learners' anxieties: Tertiary-level strategies among Omanis," in Bridging the Gap between Education and Employment: English Language Instruction in EFL Contexts, Peter Lang AG, 2015, pp. 215-228. https://doi.org/10.3726/ 978-3-0351-0842-2/19

[10] Y. Liu, "Social media tools as a learning resource," J. Educ. Technol. Dev. Exch., vol. 3, no. 1, p. $8,2010$.

[11] M. Y. Abdullah, H. M. H. Al Ghafri, and K. S. H. Al Yahyai, "A Qualitative Study on the Best Motivational Teaching Strategies in the Context of Oman: Perspectives of EFL Teachers.," English Lang. Teach., vol. 12, no. 3, pp. 57-64, 2019. https://doi.org/10.5539/ elt.v12n3p57

[12] M. Y. Abdullah, S. Hussin, and M. Shakir, "The effect of peers' and teacher's E-feedback on writing anxiety level through CMC applications," Int. J. Emerg. Technol. Learn., vol. 13, no. 11, pp. 196-207, 2018, https://doi.org/10.3991/ijet.v13i11.8448.

[13] M. Grgurovic, "Technology-enhanced blended language learning in an ESL class: A description of a model and an application of the Diffusion of Innovations theory," 2010. https ://doi.org/10.31274/etd-180810-1538

[14] R. Khalil, M. Rania, and S. S. Fahim, “Assessment as a Learning Tool in a Flipped English Language Classroom in Higher Education," in ASELS Annual Conference Proceedings, 2016, pp. 4-19.

[15] S. A. Elian and D. A. Hamaidi, "The effect of using flipped classroom strategy on the academic achievement of fourth grade students in Jordan," 2018.

[16] M. Y. Abdullah, S. Hussin, and K. Ismail, "Implementation of Flipped Classroom Model and Its Effectiveness on English Speaking Performance,” Int. J. Emerg. Technol. Learn., vol. 14, no. 09, pp. 130-147, 2019. https://doi.org/10.3991/ijet.v14i09.10348

[17] M. Y. Abdullah, S. Hussin, Z. M. Hammad, and K. Ismail, "Exploring the Effects of Flipped Classroom Model Implementation on EFL Learners' Self-confidence in English Speaking Performance," in Recent Advances in Intelligent Systems and Smart Applications, 2020, pp. 223-241. https://doi.org/10.1007/978-3-030-47411-9 13

[18] M. Y. Abdullah, S. Hussin, and K. Ismail, "Investigating the effects of the flipped classroom model on Omani EFL learners' motivation level in English speaking performance," Educ. Inf. Technol., vol. 24, no. 5, pp. 2975-2995, 2019. https://doi.org/10.1007/s10639$\underline{019-09911-5}$

[19] N. Zarei and S. Hussin, "Impact of learning management blog on students' language learn-

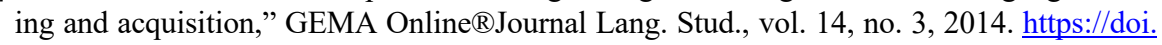
org/10.17576/gema-2014-1403-04

[20] J. C. McCroskey, "Measures of communication-bound anxiety," 1970.

[21] E. K. Horwitz, M. B. Horwitz, and J. Cope, "Foreign language classroom anxiety," Mod. Lang. J., vol. 70, no. 2, pp. 125-132, 1986. https://doi.org/10.1111/j.1540-4781.1986.tb052 $\underline{56 . X}$

[22] D. J. Young, “An investigation of students' perspectives on anxiety and speaking," Foreign Lang. Ann., vol. 23, no. 6, pp. 539-553, 1990.

[23] N. J. Salkind, Encyclopedia of measurement and statistics. SAGE publications, 2006.

[24] J. Bergmann and A. Sams, Flip your classroom: Reach every student in every class every day. International society for technology in education, 2012. https://doi.org/10.1177/07398 $\underline{9131401100120}$ 
[25] J. L. Bishop, M. A. Verleger, and others, "The flipped classroom: A survey of the research," in ASEE national conference proceedings, Atlanta, GA, 2013, vol. 30, no. 9, pp. $1-18$.

[26] Ü. Çakiroğlu and M. Öztürk, "Flipped classroom with problem-based activities: Exploring self-regulated learning in a programming language course," Educ. Technol. Soc., vol. 20, no. 1, pp. 337-349, 2017, doi: 10.1016/j.icarus.2004.04.004.

[27] P. M. Lightbown and N. Spada, how languages are learned 4th edition-Oxford Handbooks for Language Teachers. Oxford university press, 2013. https://doi.org/10.3138/cmlr.52.2. $\underline{340}$

[28] M. Webb, E. Doman, and K. Pusey, "Flipping a Chinese university EFL course: What students and teachers think of the model," J. Asiat., vol. 11, no. 4, pp. 53-87, 2014.

[29] N. Kang, "The Comparison between Regular and Flipped Classrooms for EFL Korean Adult Learners I. INTRODUCTION,” pp. 41-72, 2015. https://doi.org/10.15702/mall.20 $\underline{15.18 .3 .41}$

[30] L. Lee, "Focus-on-form through collaborative scaffolding in expert-to-novice online interaction," Lang. Learn. Technol., vol. 12, no. 3, pp. 53-72, 2008.

[31] D. Wood, How Children Think and Learn, eTextbook. John Wiley \& Sons, 2010.

\section{Authors}

Mohamad Yahya Abdullah is an Iraqi PhD candidate, English Language Studies. $\mathrm{He}$ is currently deputy of the head of English Department at Buarimi University College. He is majoring Applied Linguistics. His research interests include Teaching English as Foreign Language, Blended Learning, and Flipped Learning, Information and Communication Technology.

Supyan Hussin is a Malaysian Professor at the Faculty of Social Sciences and Humanities, Universiti Kebangsaan Malaysia. He is currently the Director of the Institute of the Malay World \& Civilization (ATMA), UKM. He is specializing in language education and technology. He has published seven books and more than 200 articles in chapters in books, journals, and proceedings at national and international levels.

Kemboja Ismail (PhD) is a Malaysian senior lecturer at the Faculty of Social Sciences and Humanities, Universiti Kebangsaan Malaysia. She was the Head of English Language Studies Programme at the Center for Literacy and Sociocultural Transformation from 2014 - April 2018. Her research interests include Academic Reading and Writing, Assessment, e-Learning and multimodality in teaching and learning.

Article submitted 2020-07-10. Resubmitted 2020-09-04. Final acceptance 2020-09-06. Final version published as submitted by the authors. 


\section{Appendix}

\subsection{Anxiety in English Speaking Performance Questionnaire (AESPQ)}

\begin{tabular}{|c|c|c|c|c|c|c|}
\hline NO. & Items & SD & D & $\mathbf{N}$ & $\mathbf{A}$ & SA \\
\hline 1. & $\begin{array}{l}\text { I get nervous and forget words and ideas I know in } \\
\text { English speaking class. }\end{array}$ & 1 & 2 & 3 & 4 & 5 \\
\hline 2. & $\begin{array}{l}\text { I get nervous and shy when my teacher asks me to speak } \\
\text { in English. }\end{array}$ & 1 & 2 & 3 & 4 & 5 \\
\hline 3. & $\begin{array}{l}\text { I feel anxious while I am waiting my turn to speak } \\
\text { English. }\end{array}$ & 1 & 2 & 3 & 4 & 5 \\
\hline 4. & $\begin{array}{l}\text { I feel anxious when I speak in English even if I am } \\
\text { prepared. }\end{array}$ & 1 & 2 & 3 & 4 & 5 \\
\hline 5. & $\begin{array}{l}\text { I feel relaxed to speak in English inside or outside } \\
\text { classroom. }\end{array}$ & 1 & 2 & 3 & 4 & 5 \\
\hline 6. & $\begin{array}{l}\text { I am confused and jumble my thoughts when I speak } \\
\text { before the audience. }\end{array}$ & 1 & 2 & 3 & 4 & 5 \\
\hline 7. & $\begin{array}{l}\text { I can feel my heart pounding when I am asked to speak } \\
\text { in English. }\end{array}$ & 1 & 2 & 3 & 4 & 5 \\
\hline 8. & $\begin{array}{l}\text { I find it difficult to control my body movements while I } \\
\text { am speaking in English. }\end{array}$ & 1 & 2 & 3 & 4 & 5 \\
\hline 9. & $\begin{array}{l}\text { I avoid an eye to eye contact with the audience while } \\
\text { speaking in English. }\end{array}$ & 1 & 2 & 3 & 4 & 5 \\
\hline 10. & $\begin{array}{l}\text { I start sweating and shaking just before giving a speech } \\
\text { in English. }\end{array}$ & 1 & 2 & 3 & 4 & 5 \\
\hline 11. & $\begin{array}{l}\text { I am afraid that other students may laugh at me while I } \\
\text { am speaking in English. }\end{array}$ & 1 & 2 & 3 & 4 & 5 \\
\hline 12. & $\begin{array}{l}\text { I feel comfortable when no one pays attention to my } \\
\text { errors when I speak in English. }\end{array}$ & 1 & 2 & 3 & 4 & 5 \\
\hline 13. & $\begin{array}{l}\text { I get nervous if my classmates correct my errors while I } \\
\text { am speaking in English. }\end{array}$ & 1 & 2 & 3 & 4 & 5 \\
\hline 14. & $\begin{array}{l}\text { I feel relaxed and speak English fluently when the } \\
\text { teacher ignores some of my mistakes. }\end{array}$ & 1 & 2 & 3 & 4 & 5 \\
\hline 15 & $\begin{array}{l}\text { I fear that other students might speak English better than } \\
\text { me in group discussion. }\end{array}$ & 1 & 2 & 3 & 4 & 5 \\
\hline 16. & I don't feel relaxed when I speak English in group work. & 1 & 2 & 3 & 4 & 5 \\
\hline 17. & $\begin{array}{l}\text { I don't feel comfortable when I have to give individual } \\
\text { presentation in English. }\end{array}$ & 1 & 2 & 3 & 4 & 5 \\
\hline 18. & $\begin{array}{l}\text { I get nervous in any speech activity because my English } \\
\text { is poor. }\end{array}$ & 1 & 2 & 3 & 4 & 5 \\
\hline
\end{tabular}

